\title{
Evaluation of the Repeated Exposure of Hexaflumuron on Liver and Spleen Tissues and Its Mutagenicity Ability in Male Albino Rat
}

\author{
Mohamed A. Noaishi*, H. H. Abd alhafez, and Sanaa A. Abdulrahman \\ Mammalian and Aquatic Toxicology Department, Central Agricultural Pesticides Lab. (CAPL), Agricultural \\ Research Center, Ministry of Agriculture, Egypt. \\ "Corresponding author: Mohamed Abdelfattah Noaishi, Mobile: +201004088153, Email: noaishi@ gmail.com
}

\begin{abstract}
Background: Hexaflumuron (HFM) is an insect growth regulator (IGR); it is highly effective against a wide range of pests. Aim of the work: Due to the lack of toxicological assessments of this insecticide especially the formulation type, the objective of the present study was aimed to investigate the toxicological effects of repeated exposure of HFM formulation on adult albino rats. Materials and methods: Three groups were administered daily by gavage for (28 days) at dose of 11, 4, and $2.5 \mathrm{mg} / \mathrm{kg}$ b.wt respectively. In addition to control group. Results: The results of acute toxicity indicated HFM exhibited moderate to some extent high toxicity toward the treated rats. Slight tremors and bleeding from nose were observed. The repeated exposure results revealed the high and middle doses exhibited methemoglobinemia. Also, the HFM treatment led to increase in AST and ALT levels. The urea and creatinine levels were not significantly increased except the level of creatinine in high dose. According to the histopathological findings the middle and low doses of HFM revealed greater injurious in liver and spleen tissues than induced by high dose. HFM induced a statistically significant increase in the micronucleus (MN) frequency in a dose-dependent manner compared with a negative control group. Conclusion: So, it is obvious the middle and low doses induced damage in the liver and spleen organs while the high dose induced damage in blood, bone marrow, and kidney organs.
\end{abstract}

Keywords: Hexaflumuron, histopathology, spleen, liver, methemoglobinemia, micronucleus assay.

\section{INTRODUCTION}

Hexaflumuron is a Benzoylphenyl urea (BPU) insecticides; it is an insect growth regulator (IGR) that works by inhibiting a chitin synthesis. It disrupts the molting process in insects, which results in death at immature stages. It is highly effective against a wide range of pests, primarily in Lepidoptera, Coleoptera, Homoptera and Diptra. In Egypt, this insecticide is used for control tuta absoluta insect in tomatoes and cotton leaf worm and boll worms ${ }^{(\mathbf{1})}$. The acute oral LD50 of HFM as un active ingredient for rats is more than $5000 \mathrm{mg} / \mathrm{kg}$ b.wt. It is classified as unlikely to be hazard ${ }^{(2)}$. But the toxicity of the HFM formulation may differ from that of the active ingredient. A previous study reported that the estimated LD50 of the HFM formulation (locally made) were 110 and $105 \mathrm{mg} / \mathrm{kg}$ b.wt for male and female respectively (unpublished data). In addition, the treated rats exhibited nose bleeding and noticeable tremors in neck. Death happened after several days of administration. So the big difference in LD50 value between the active ingredient and the formulation was of concern. This observation leads to investigate the toxicity and the side effects of this insecticide especially the formulation type. But unfortunately there is limited literature available on the toxicity of HFM on nontarget organisms, and diflubenzuron (DFB) is another haloaromatic substituted of (BPUs) with an analogous insecticidal mode of action and has similar toxicological properties, so, we review the toxicity of DFB as additional reference. Also DFB is considered the first discovered insecticide of BPUs group. A pharmacological research recently disclosed that
DFB binding with a sulfonylurea receptor (SUR) is the target of chitin synthesis inhibition in the drosophila melanogaster insect ${ }^{(3)}$. But later Meyer $\boldsymbol{e t}$ al. ${ }^{(4)}$ suggested that the (SUR) is dispensable in drosophila melanogaster embryos for chitin synthesis and other factors may be involved in chitin synthesis. In the mammalian it is created that SUR receptors and their agents, e.g. (BPUs), work together to boost the endogenous release of insulin from pancreatic $\beta$ cells. And the significant negative impact of sulfonylureas agents is hypoglycemia, which can be a significant problem in extended treatment ${ }^{(5)}$. Other mode of toxicity of (BPUs); is attributed to the ability to induce methemoglobinemia, an abnormal form of hemo-globin, the iron in the molecule of hemoglobin is converted to its trivalent oxidation state $\left(\mathrm{Fe}^{3+}\right)$ instead of its common divalent state $\left(\mathrm{Fe}^{2+}\right)$. This shift in the hemoglobin molecule converts it into oxidized hemoglobin and has become inappropriate for the transport of oxygen, resulting in certain kinds of illnesses called methemoglobinemia (6). Methemoglobinemia may be inherited or acquired from the environment, but the acquired form is more frequently caused by different drugs and toxins ${ }^{(7)}$. Previous literature revealed the acute oral studies in rats and mice with active substance 25\% DFB indicated marginal effects on methemoglobin levels at a dose of $10 \mathrm{~g} / \mathrm{kg} \mathrm{b.wt}{ }^{(8)}$. Same observ-ation on dietary dogs study $(8.3 \mathrm{mg} / \mathrm{kg} /$ day for 28 days $)$ of technical HFM elevated methemoglobin levels in both sexes ${ }^{(9)}$. Also in fish study the DFB $(25 \mathrm{mg} / \mathrm{L})$ caused a reduction in the number of erythrocytes and hemoglobin content after $96 \mathrm{~h}$ of exposure ${ }^{(\mathbf{1 0})}$. These previous findings concluded that BPU compounds 
may induce injures on the non-target organisms by affecting with different mode of toxicity.

It is also well-known; histopathology is a crucial part of the toxicological and risk assessment of drugs and chemicals. It is essential to clarify unbiased findings on the experimental organism ${ }^{(11)}$. The investigation of histopathological modifications in animal tissues is a sensitive and quick technique for assessing the toxic potential and risk assessment of chemicals in the environment ${ }^{(\mathbf{1 2})}$.

As well as, cytogenetic analysis gives valuable information about mutagenic potentiality of the tested material. Exposure to the mutagens may induce its effect in the blood or bone marrow in treated animals ${ }^{(\mathbf{1 3})}$. Presently, micronucleus assay serves as an important endpoint to detect the genetic damage by chemicals in the cells of the organisms. Micronucleus methods are rapid and easy to learn, and have comparable sensitivity. For these reasons, micronucleus assays are being used with increasing regularity Adler ${ }^{(14)}$. Therefore, the present study aimed to evaluate the repeated exposure effect of hexaflumuron formulation on the male albino rats, especially the probability of HFM to induce methemoglobinemia status in the treated rats. The study was designed to evaluate the side effect of this formulation on the liver and spleen tissues as the main target organs. In addition to some parameters that covered liver and kidney functions, and the mutagenicity ability.

\section{MATERIALS AND METHODS}

\section{The tested insecticide (HFM)}

The tested insecticide used in this study was a commercial insecticide (local made) with active ingredients of hexaflumuron $10 \%$, the IUPAC name: 1-[3,5-dichloro-4-(1,1,2,2-tetrafluoroethoxy) phenyl]-3-(2,6-difluorobenzoyl)urea. The formulation was supplied as emulsifiable concentrate (EC) by the Mammalian Toxicology Department, Central Agricultural Pesticides Lab, Dokki, Egypt.

\footnotetext{
Animals

Healthy male albino rats (Rattus norvegicus) of Wistar strain weighing $120 \mathrm{~g} \pm 10 \%$ were used throughout the whole study. The animals were obtained from the laboratory animal house of the National Research Center, Dokki, Egypt. Animals were kept under full hygienic conditions, had free access to fresh water and fresh well-balanced diet, and kept under supervision for two weeks before commencing the experimental work. The animals were housed in all groups of five rats per cage. Procedures for animals and their care were carried out in accordance with the ethical guidelines for laboratory animals of Mammalian and Aquatic Toxicology Department.
}

Experimental design

\section{Median lethal dose (LD50) study}

Determination of the oral LD50 (median lethal dose) was conducted to provide preliminary data on the toxic nature of the formulation being tested for which no other toxicology data is accessible. In this study, experimental animals were fasted for $18 \mathrm{hrs}$ prior to dosing. The HFM was dissolved in distilled water $(d / w)$ and administered once a single dose orally by gavage to the rats, using stomach feeding tube. The volume of the dose depends on the weight of the rats. The dose didn't exceed $1 \mathrm{ml} / 100 \mathrm{~g}$ b.wt. A total of 30 apparently rats were randomly divided into six groups; each of it has five rats. The first group was used as a pilot test to determine the range of dose levels in the main study. The second group was kept as control group and given dissolving vehicle $(1 \mathrm{ml}$ $(\mathrm{d} / \mathrm{w}) / 100 \mathrm{~g} \mathrm{~b} \cdot \mathrm{wt})$. The other four groups were administered at four dose levels 56, 82, 119, and 175 $\mathrm{mg} / \mathrm{kg}$ b.wt respectively. The rats were observed individually at least once during the first 30 minutes after dosing, then periodically during the first 24 hours and daily for a total of 14 days. The signs of toxicity and mortality were recorded during the observation period. The calculation method of the LD50 was carried out according to method of Weil, (15). When the mortality data (r-values) were recorded, the f-values were obtained from the tables. The LD50 was calculated from the following equation: $\log m=\log D+d(f+1)$, Where: $\log m=$ the logarithm of the LD50, $\log \mathrm{D}=$ the logarithm of the lowest dose, $d=$ the logarithm of the constant ratio $(=1.46)$ between dosage levels.

\section{Repeated exposure study}

A total of 20 apparently rats were randomly divided into four groups. The first group was kept as control and given just $(1 \mathrm{ml}(\mathrm{d} / \mathrm{w}) / 100 \mathrm{~g}$ b.wt). Other three groups were administered by gavage at dose of 11,4 , and $2.5 \mathrm{mg} / \mathrm{kg} \mathrm{b} . \mathrm{wt}$ which were equivalent to $1 / 10,1 / 30$, and 1/50 of estimated LD50 respectively. The administration of HFM was daily and continues for (28 days). The signs of toxicity and the body weights of rats were recorded periodically ${ }^{(16)}$.

\section{Blood and organs collection}

Rats were sacrificed by euthanasia at the end of treatments. Blood samples were collected in sodium heparin tubes for plasma samples, and then the samples were centrifuged at $3000 \mathrm{rpm}$ for $20 \mathrm{~min}$ and stored at $-20^{\circ} \mathrm{C}$ to be used for liver and kidney biochemical parameters. Liver and spleen organs were immediately removed and washed using chilled saline solution and were preserved in formalin $(10 \%$, w/v) for histological parameter.

\section{Ethical approval:}

This study was conducted in accordance with ethical procedures and policies approved by 
Animal Care and Use Committee of Agricultural Research Center.

\section{Histological parameter}

After liver and spleen specimens were preserved in $10 \%$ formalin for $24 \mathrm{hrs}$. The decalcification process was occurred by fixed in formic acid then washed in tap water. Serial dilutions of alcohol (absolute ethanol) were used for dehydration. Specimens were cleared in xylene and embedded in paraffin at $56^{\circ} \mathrm{C}$ in hot air oven for $24 \mathrm{hrs}$. Paraffin bees wax tissue blocks were prepared for sectioning at 4 microns thickness by sledge microtome. The obtained tissue sections were collected on glass slides, deparaffinized, stained by hematoxylin and eosin stain, then examination was done through the light microscope ${ }^{(\mathbf{1 7})}$.

\section{Hemoglobin and methemoglobin parameters}

The hemoglobin $(\mathrm{Hb})$ was determined by using kit from Diamond diagnostic Company, Egypt. The methemoglobin (MetHb) was determined according to Leahy and Smith ${ }^{(18)}$ procedure.

\section{Liver and kidney functions parameters}

All biochemical measurements were determined in plasma according to the details given in the kit's instructions and performed by using a Jasco UV-VIS spectrophotometer V-630 PC (Japan).

\section{Mutagenicity assay}

The monitoring of micronucleated normochromatic erythrocytes (NCE) in bone-marrow was performed according to the procedure described by Schmid ${ }^{(19)}$ with some modifications recommended by $\operatorname{Adler}^{(14)}$.

\section{Statistical analysis}

One-way ANOVA followed by the HolmSidak test were used to determine differences between groups for all parameters. The results are presented as mean \pm standard error of mean (SEM). Values were considered statistically significant if $\mathrm{P}<0.05$. The SigmaPlot statistics software, Ver.11 was used for the statistical analysis.

\section{RESULTS}

\section{LD50 of HFM and symptoms of toxicity}

The estimated oral $\mathrm{LD}_{50}$ of HFM was $115 \mathrm{mg} / \mathrm{kg}$ b.wt for adult male rats. The symptoms of toxicity manifested by the animals began to appear 2 days after the administration. The main observed symptoms were slight tremors, and bleeding from nose. Finally, paralysis happened and followed by death after 4 days, 7 days and 14 days from administration. The recovery happened in some treated animals at low and middle doses only after the observation period (14 days).

\section{Repeated exposure and the body weight}

After repeated exposure, it was observed HFM at three doses did not cause death and there were no signs of toxicity observed on treated rats but some behavioral changes in the animals were observed. The main observation was increasing in the water and food consumption after 3 weeks at high and middle doses while in low dose this was not observed (data not shown). However, treated animals showed normal increase of the body weight when compared with control group (Fig 1).

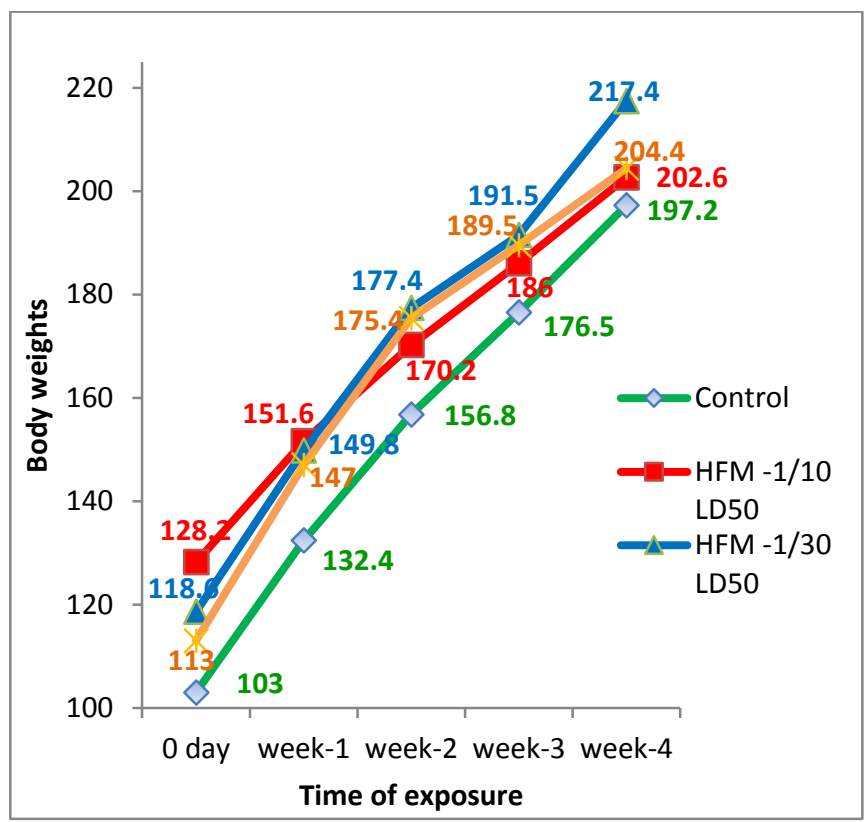

Fig. (1) The correlation between the time of exposure of HFM and the mean of body weights of control and treatment groups

Hematological and Biochemical significant change in $\mathrm{Hb}$ levels in three treatment groups when compared to control group. But there was a statistically significant increase in MetHb in high and middle doses. Also The HFM treatment induced injury effect on liver functions which led to increase in AST and ALT levels especially in middle dose but this increase was not significant when compared to control group. The other biochemical parameters of liver functions (ALP, Alb, and total protein levels) were not significantly changed than control group. While the kidney function parameters e.g. (urea and creatinine levels) showed Analyses

There was no statistically significant increase in creatinine level at high dose in relation to the control group (Table 1). 
ejhm.journals.ekb.eg

Table (1): Hematological and Biochemical parameters in the plasma of rats treated with the HFM

\begin{tabular}{lcccc}
\hline Parameters & Control group & $\begin{array}{c}\text { High dose } \\
=(1 / 10 \text { LD50 })\end{array}$ & $\begin{array}{c}\text { middle dose } \\
=(1 / 30 \text { LD50 })\end{array}$ & $\begin{array}{c}\text { Low dose } \\
=(1 / 50 \text { LD50 })\end{array}$ \\
\hline $\mathrm{Hb}(\mathrm{g} / \mathrm{dl})$ & $20.47 \pm 0.68$ & $19.76 \pm 0.83$ & $22.40 \pm 1.25$ & $21.971 \pm 0.82$ \\
$\mathrm{MetHb}(\mathrm{g} / \mathrm{dl})$ & $3.02 \pm 0.35$ & $3.48 \pm 0.28^{*}$ & $5.21 \pm 0.45^{*}$ & $4.324 \pm 0.52$ \\
\hline $\mathrm{AST}(\mathrm{U} / \mathrm{ml})$ & $38.76 \pm 5.08$ & $45.89 \pm 7.58$ & $61.16 \pm 3.86$ & $48.23 \pm 7.41$ \\
$\mathrm{ALT}(\mathrm{U} / \mathrm{ml})$ & $42.05 \pm 4.99$ & $46.43 \pm 2.54$ & $53.41 \pm 6.26$ & $44.49 \pm 2.76$ \\
$\mathrm{ALP}(\mathrm{U} / \mathrm{L})$ & $28.67 \pm 1.53$ & $34.78 \pm 1.78$ & $31.61 \pm 1.09$ & $26.94 \pm 3.10$ \\
$\mathrm{Alb}(\mathrm{U} / \mathrm{L})$ & $5.082 \pm 0.28$ & $4.36 \pm 0.13$ & $5.30 \pm 0.20$ & $4.24 \pm 0.29$ \\
$\mathrm{~T}$. Protein & $341.97 \pm 25.58$ & $404.12 \pm 63.24$ & $415.78 \pm 65.87$ & $378.71 \pm 85.56$ \\
\hline Urea $(\mathrm{mg} / \mathrm{dl})$ & $5.51 \pm 0.78$ & $7.561 \pm 0.074$ & $6.17 \pm 0.69$ & $6.17 \pm 0.81$ \\
Creatinine $(\mathrm{mg} / \mathrm{dl})$ & $42.28 \pm 1.50$ & $50.64 \pm 2.67^{*}$ & $46.044 \pm 1.85$ & $37.90 \pm 3.52$ \\
\hline
\end{tabular}

Values are from five animals in each group and expressed as mean \pm SEM of each group; *Significant change compared to control group at $\mathrm{p}<0.05$.

\section{Histopathology of liver tissues}

Histopathological examination of liver specimens taken from control group showed normal histological structure of the central vein and surrounding hepatocytes in the parenchyma. High dose group demonstrated congestion of portal blood vessel and portal infiltration with inflammatory cells. Moreover, livers of rats treated with middle and low doses revealed greater injurious than induced by high dose. It is obvious by occurrence necrosis of sporadic hepatocytes, fibroplasia in the portal triad and portal infiltration with inflammatory cells while low dose group demonstrated fibroplasia in the portal triad with appearance of newly formed bile ductules (Fig. 2).
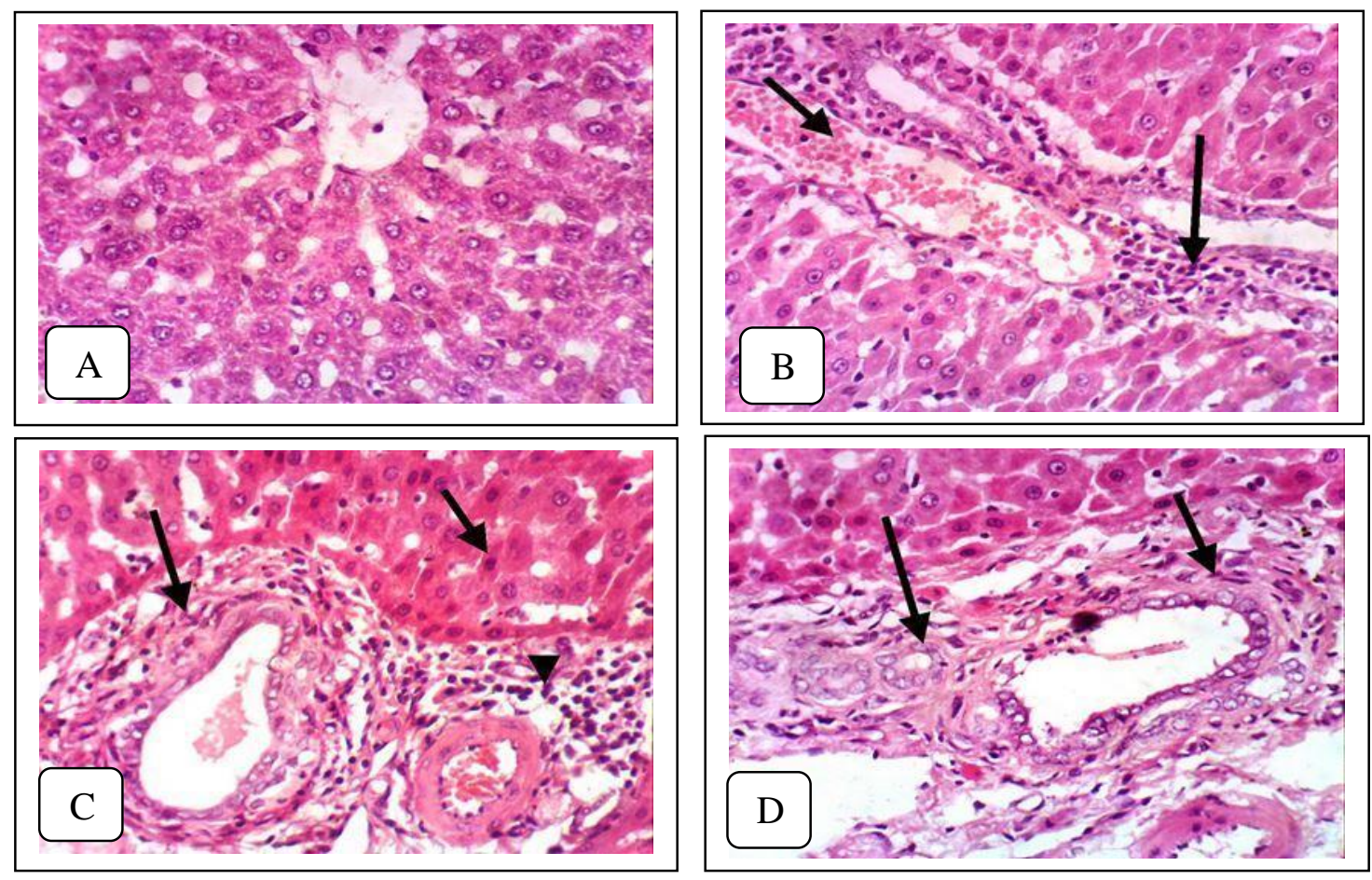

Fig (2) Light micrographs of the rats liver tissue show as follow: (A), control group showing normal histological structure of hepatocytes; (B); high dose group showing congestion of portal blood vessel and portal infiltration with inflammatory cells; (C), middle dose group showing necrosis of sporadic hepatocytes, fibroplasia in the portal triad and portal infiltration with inflammatory cells; and (D) low dose group showing fibroplasia in the portal triad with appearance of newly formed bile ductules (H and E X 400) 


\section{Histopathology of spleen tissues}

The histopathological examination of spleen specimens of control group showed normal lymphoid follicle but the HFM treatments showed interesting result. The high dose group revealed slight lymphocytic necrosis and depletion with noticeable increase in spleen size compared to the control group. While the middle and low doses showed lymphocytic necrosis and depletion with appearance of tangible body macrophages (Fig. 3).
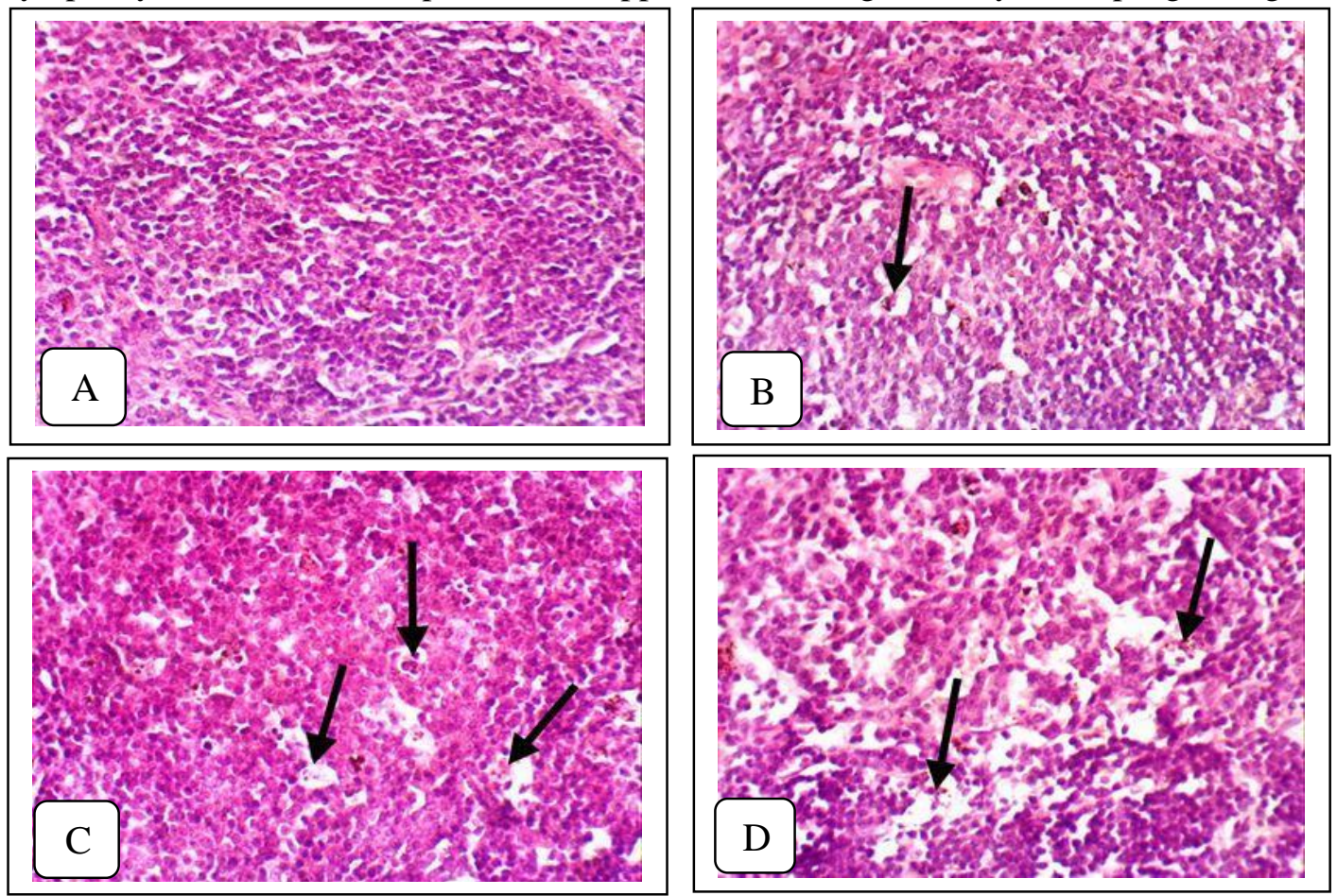

Fig (3) Light micrographs of the rats spleen tissue show as follow: (A), control group showing normal lymphoid follicle; (B) and (C); high and middle dose groups showing slight lymphocytic necrosis and depletion; and (D) low dose group showing lymphocytic necrosis and depletion with appearance of tangible body macrophages ( $\mathrm{H}$ and $\mathrm{E}$ $\mathrm{X} 400)$

\section{Mutagenic analysis}

The data presented in table (2) revealed that, the high and middle doses of HFM induced significant increase of micronuclei frequency in the bone marrow cells. Low dose did not induce significant increase. Also there are significant differences between high and middle dose groups and between high and low dose groups. The data exhibited dose a dose-dependent response.

Table 2: The numbers of micronuclei frequency in rats bone marrow cells after HFM treatment

\begin{tabular}{|c|c|c|c|c|c|}
\hline \multirow{2}{*}{ Treatments } & \multicolumn{3}{|c|}{ No. of micronuclei in the cell } & \multirow{2}{*}{$\begin{array}{l}\text { Total No. of } \\
\text { micronucleated } \\
\text { cells }\end{array}$} & \multirow{2}{*}{ Mean \pm SEM } \\
\hline & 1 & 2 & $\geq 3$ & & \\
\hline Control group & 26 & 7 & 5 & 38 & $7.60 \pm 0.93$ \\
\hline $\begin{array}{c}\text { Low dose } \\
\text { (1/50 LD50) }\end{array}$ & 41 & 6 & 6 & 53 & $10.60 \pm 0.87$ \\
\hline $\begin{array}{l}\text { Middle dose } \\
\text { (1/30 LD50) }\end{array}$ & 51 & 13 & 7 & 71 & $14.20^{* *} \pm 1.20$ \\
\hline $\begin{array}{l}\text { High dose } \\
\text { (1/10 LD50) }\end{array}$ & 104 & 19 & 15 & 138 & $27.60^{* * *} \pm 1.44$ \\
\hline
\end{tabular}

Values are from five rats in each group and the last column represent mean \pm S.E.M of micronuclei per 1000 PCE/NCE; ${ }^{* * *}$ Significant change compared to control group at $\mathrm{p}<0.001{ }^{* * *}$ Significant change compared to control group at $\mathrm{p}<0.01$ 


\section{DISCUSSION}

The results of acute toxicity indicated that HFM exhibited moderate to some extent high toxicity toward the treated rats. On the contrary the previous literature reported that the acute toxicity of HFM as an active ingredient is low and the LD50 is exceeding $5000 \mathrm{mg} / \mathrm{kg} \mathrm{b.wt}{ }^{(2)}$. May be the big different between the LD50 value of active ingredient and the HFM formulation is due to the impurities or second products that accompanying with the active ingredient. One of the problems of the HFM insecticide is no declared impurities of the active ingredient in the FAO. All impurities have been claimed confidential ${ }^{(9)}$. More additional, the signs of toxicity which were observed on the treated rats like tremors and bleeding from nose may due to the unknown impurities or metabolites of active ingredient. One of the metabolites of DFB is 4chloroaniline (PCA). Although this metabolite was detected at very low concentrations in urine of rats given a high dose of DFB ${ }^{(20)}$, it is associated with the majority of the severe health effects found in animal studies, particularly cancer of the spleen, liver and osteosarcomas in male rats ${ }^{(21)}$. In addition, the repeated exposure of HFM indicated increasing in water and food consumption after 3 weeks from starting of dosing. This is may be due to HFM, as one of sulfonylurea agents, acts directly on the pancreatic $\beta$-cell to induce insulin secretion; this is done by binding the cytosolic surface of the sulfonylurea receptor, which causes ATP-sensitive potassium channels to be closed, followed by plasma membrane depolarization, calcium channel opening and insulin exocytosis ${ }^{(22)}$. So, excess of insulin secretion lead to hypoglycemic symptoms and hunger which increase food intake ${ }^{(23)}$.

Other side effect of repeated exposure of HFM is the significant increase of methmeglobin levels in high and middle doses. As above mentioned a methemoglobinemia is a blood disorder in which too little oxygen is reached to the body cells. Acquired methemoglobinemia is induced by exposure to certain drugs, chemicals or foods ${ }^{(7)}$. Many previous studies revealed that the repeated exposure to HFM by oral route in subacute studies (rats, mice, and dogs), or in subchronic studies (mice and rats) lead to increase in methemoglobin level and was considered the critical adverse effect for the risk assessment and NOAEL setting ${ }^{\left({ }^{(9)}\right.}$. Moreover the rats were exposed for 3 weeks by inhalation to technical grade of DFB showed methemoglobin levels in the two lower concentrations, significantly higher than those of the control animals. Also the metabolite of DFB (PCA) caused significant increase in methemoglobinemia at dose of $62 \mathrm{mg} / \mathrm{kg}{ }^{(24)}$. Thus, HFM or DFB metabolites may be engaged in causing methemoglobinemia. Also, HFM metabolism appears to be broad with little parent compound still identified after exposure. Some metabolites of HFM include compounds that have several chemical groups e.g. (2,6-difluorobenzoic acid, 2,6-difluorobenzamide, 3,5-dichloro-4-(1,1,2,2-tetrafluoroethoxy) aniline and 1-(3,5-dichloro-4-(1,1,2,2-tetrafluoroethoxy) phenyl) urea ${ }^{(9)}$. Therefore, may one of these metabolites or others is responsible for inducing methemoglobinemia state.

On the other hand, the liver is the target organ for detoxification and necessary for the metabolism of xenobiotic compounds ${ }^{(25)}$. The levels of liver enzymes AST, ALT and ALP in the blood plasma are some of the most sensitive biomarkers for liver damage because they are released into the blood after intracellular damage ${ }^{(26)}$. High levels of AST and ALT are associated with hepatic necrosis, hepatitis and hepatic toxicity ${ }^{(27)}$. In the present study, repeated exposure to HFM led to partly increase in AST and ALT levels in the middle and low doses. However, this increase was not of clinical significance. These results of liver function are complementary with the results of liver histopathology. Leukocytosis which was observed in liver and spleen tissues after HFM treatments is reflected by inflammatory cells infiltration and is considered as a defensive mechanism ${ }^{(28)}$. Leukocytosis is often related to infections, poisoning and metabolic disturbances or other prevalent causes such as malignancies ${ }^{(29)}$. Also the necrosis which was observed in liver and spleen tissues may be attributed to hypoxia or reduced the oxygen in the blood as a consequence of methemoglobinemia occurred in treated rats. Hypoxia leads to both necrosis and apoptosis ${ }^{(30)}$. This finding is complementary with previous freshwater fish study that exposed fish to $(0.25,0.50$ $\mathrm{mg} / \mathrm{L}$ of DFB for 14 days) and found histopathological changes and slight to moderate damage in gills and livers of fish ${ }^{(31)}$. The other noticeable observation in this study was that the middle and low doses induced more effect than high dose. It was obvious in the liver and spleen histopathology result which showed lymphocytic necrosis and depletion more than that induced by high dose. Also Barros et al. ${ }^{(32)}$ found similar finding when the subacute exposure to the lowest dose of DFB caused significant decrease in reproduction of male rats than induced by high dose. One possible explanation for this could be that chemical makes their effects like the endocrinedisrupting chemicals (EDCs) that can make effects at low doses, which are not predicted at high doses ${ }^{(33)}$. Other explanation is that the role of kidneys which are primarily organs of excretion. The treatments with high-doses of that compound make stress on the 
kidney and stimulate to rapidly clearance of their metabolites from the body than those happened in low doses. But this stress on the kidney is associated with the risk of kidney injury.

Changes in the plasma creatinine concentration reflect changes in the glomerular filtration rate in relation to renal function ${ }^{(34)}$. Determination of creatinine in serum is the most common technique used to assess renal function ${ }^{(35)}$. It was observed that animals treated with high dose of HFM showed significant increase of creatinine levels, with no change in the urea levels. The middle and low doses did not induce significant effect on kidney functions. It is established that the nephrotoxicity of any xenobiotic is dose-dependent. As supplement to investigate our results, the mutagenic study showed increase in micronuclei in high and middle doses. It could explain that erythrocytes which were destructed in the spleen and liver tissues are related to stimulation of erythrocytes regeneration in the bone marrow. This stimulation may lead to uncontrol in dividing cells and may lead to increase of micronuclei frequency in bone marrow. Also it is possible that this insecticide exerted its genotoxic effects on bone marrow cells. So, from previous findings and present study it seems that hexaflumuron (HFM) may has harmful effects on non-target organisms and it could not be rule out the possibility of the metabolites and impurities to lead to more toxicity than the parent compound.

\section{CONCLUSION}

These findings unveiled the hazardous effects of hexaflumuron repeated exposure on the male rats, raising concerns about this insecticide that possesses a potential hazard to human health, especially low doses. More attention should be addressed to risks of low doses of HFM and further toxicological studies should be conducted to identify its toxic mechanisms. Also, it is important to note that some adverse effects may be caused by impurities and metabolites like methemoglobinemia status. Hence, it is important to do more toxicological studies about these chemicals and their impurities.

\section{REFERENCES}

1. APC (2016): Agriculture Pesticide Committee of Egypt. http://www.apc.gov.eg

2. WHO (2009): World Health Organization, recommended classification of pesticides by hazard and guidelines to classification. https://www.who.int/ipcs/publications/pesticides_hazar d_2009.pdf_(Dec, 2018).

3. Abo-Elghar GE, Fujiyoshi P, Matsumura F (2004): Significance of the sulfonylurea receptor (SUR) as the target of diflubenzuron in chitin synthesis inhibition in Drosophila melanogaster and Blattella germanica. Insect Biochem. Mol Biol., 34:743-752.
4. Meyer F, Fotenmeyer M and Moussiana B (2013): The sulfonylurea receptor Sur is dispensable for chitin synthesis in Drosophila melanogaster embryos. Pest Manag Sci., 69: 1136-1140.

5. Yu O, Azoulay L, Yin H, Filion KB, Suissa S (2018): Sulfonylureas as initial treatment for type 2 diabetes and the risk of severe hypoglycemia. Am J Med.,131(3):3

6. Cruz-Landeira A, Bal MJ, Quintela O, lopezRivadulla M (2002): Determination of methemoglobin and total hemoglobin in toxicological studies by derivative spectrophotometry. Journal of Analytical Toxicology, 26: 76-72.

7. Toker I, Yesilaras M, Caliskan-Tur $F$ and Toktas $R$ (2015): Methemoglobinemia caused by dapsone overdose: Which treatment is best? Turkish Journal of Emergency Medicine, 15: 182-184.

8. Marrs TC and Ballantyne B (2004): Pesticide Toxicology and International Regulation, John Wiley \& Sons Ltd., England, pp. 198-199.

9. European Union (2015): Assessment Report of active substances (hexaflumuron). http://dissemination.echa.europa.eu/Biocides/ActiveSu bstances/1314-18/1314-18_Assessment_Report.pdf

10. Pereira-Maduenho L and Martinez CBR (2008): Acute effects of diflubenzuron on the freshwater fish Prochilodus lineatus. Comp. Biochem. Physiol., doi:10.1016/j.cbpc.2008.06.010

11. Crissman JW, Goodman DG, Hildebrandt PK, Maronpot RR, Prater DA, Riley JH, Sea-man WJ and Thake DC (2004): Best practice guideline: toxicologic histopathology. Toxicologic Pathology, 32: 126-131.

12. Al-Qudsi $\mathbf{F}$ and Linjawi $S$ (2012): Histological and hormonal changes in rat endometrium under the effect of camphor. Life Science Journal, 9: 348-355.

13. Kehdy FS, Cerqueira EM, Bonjardim MB, Camelo RM and Castro MC (2007): Study of the cytogenetic effects of occupational exposure to pesticides on sanitation workers in Belo Horizonte, Brazil. Genet. Mol. Res., 6(3): 581-593.

14. Adler ID (1980): Cytogenetic tests in mammals, in mutagenicity testing, a practical approach, IRL Press, Oxford. PP. 275-306.

15. Weil CS (1952): Tables for convenient calculation of median effective dose (ED50 or LD50) and instructions in their use. Biometrics, 8: 249.

16. OECD (2008): Guideline for Testing of Chemicals: Repeated Dose 28-Day Oral Toxicity Study in Rodents. https://www.oecd-ilibrary.org/.../test-no-407-repeateddose-28-day-oral-toxicity-study-i

17. Banchroft JD, Stevens A and Turner D (1996): Theory and practice of histological techniques, Fourth ed. Churchil Livingstone, New York.

18. Leahy $T$ and Smith $R$ (1960): Notes on methemoglobin determination. Clinical Chemistry, 6(2): 148-152.

19. Schmid W (1975): The micronucleus test. Mutation. Res., 31: 9-15.

20. FAO/WHO (2015): Joint Meeting on Diflubenzuron. http://www.fao.org/3/a-bo070e.pdf.

21. WHO (2003): World Health Organization, Concise International
Chemical. 
http://www.who.int/ipcs/publications/cicad/en/cicad48. pdf.

22. Krentz AJ and Bailey CJ (2005): Oral antidiabetic agents: current role in type 2 diabetes mellitus. Drugs,65(3):385-411.

23. Hoffman RP (2007): Sympathetic mechanisms of hypoglycemic counterregulation. Curr. Diabetes Rev., 3(3):185-93.

24. EPA (2007): Office of Prevention, Pesticides and Toxic Substances (Diflubenzuron). http://www.fluoridealert.org/wpcontent/pesticides/EPA -HQ-OPP-2007-0446-0002.pdf.

25. Szachowicz-Petelska B, Dobrzynska I, Skrzydlewska E and Figaszewski $Z$ (2012): Protective effect of blackcurrant on liver cell membrane of rats intoxicated with ethanol. J Membr Biol., 245:191-200.

26. Ozer J, Ratner $M$, Shawc $M$, Bailey $W$ and Schomaker S (2008): The current state of serum biomarkers of hepatotoxicity. Toxicology, 245:194205.

27. Utoh-Nedosa AU, Akah PA, Okoye TC and Okoli CO (2009): Evaluation of the toxic effects of dihydroartemisinin on the vital organs of Wister Albino rats. Am J Pharm Toxicol., 4:169-173.

28. Ferrero- Miliani L, Nielsen OH, Andersen PS and Girardin SE (2007): Chronic inflammation: importance of NOD2 and NALP3 in interleukin- $1 \beta$ generation. Clinical \& Experimental Immunology, 147(2): (227-235).
29. Opdenakker G, Fibbe W and Van Damme J (1998): The molecular basis of leukocytosis. Immunology Today, 19: 182-189.

30. Shimizu S, Eguchi Y, Kamiike W, Itoh Y, Hasegawa J, Yamabe K, Otsuki Y, Matsuda $H$ and Tsujimoto Y (1996): Induction of apoptosis as well as necrosis by hypoxia and predominant prevention of apoptosis by Bcl-2 and Bcl-X. Cancer Research, 56: 2161-2166.

31. Benze TP, Sakuragui MM, Paula Zago LH and Fernandes $\mathbf{N}$ (2016): Subchronic Exposure to Diflubenzuron Causes Health Disorders in Neotropical Freshwater Fish, Prochilodus lineatus. Environ. Toxicol., 31: 533-542.

32. Barros AL, Cavalheiro GF, Souza AV, Traesel GK, Anselmo-Franci JA, Kassuya CA and Arena AC (2016): Subacute Toxicity Assessment of Diflubenzuron, an Insect Growth Regulator, in Adult Male Rats. Wiley Periodicals, Inc. Environ Toxicol., 31: 407-414.

33. Vandenberg LN, Colborn T, Hayes TB et al. (2012): Hormones and endocrine-disrupting chemicals: lowdose effects and nonmonotonic dose responses. Endocr. Rev., 33(3):378-455.

34. Rahn KH, Heidenreich S and Bruckner D (1999): How to assess glomerular function and damage in humans. J Hypertens, 17(3): 309-317.

35. Thomas $C$ and Thomas $L$ (2009): Renal Failure, Measuring the Glomerular Filtration Rate, Review Article, Deutsches Ärzteblatt International, 106(51-52): 849-54. 